\title{
Intradural Extramedullary Ganglioneuroma: Case Report and Review of the Literature
}

\author{
David I. Levy, M.D., Michael N. Bucci, M.D., Lee Weatherbee, M.D., \\ and William F. Chandler, M.D. \\ Section of Neurosurgery and Department of Pathology, University of Michigan, Ann Arbor, Michigan, \\ and Barrow Neurological Institute, Phoenix, Arizona
}

Levy DI, Bucci MN, Weatherbee L, Chandler WF. Intradural extramedullary ganglioneuroma: case report and review of the literature. Surg Neurol 1992;37:216-8.

The authors present a unique case of an intradural extramedullary ganglioneuroma in the thoracic spine of an adult. Intraspinal ganglioneuromas are rare, benign tumors of sympathetic nervous tissue origin, but exclusively intradural ganglioneuromas have not been reported.

KEY WORDS: Ganglioneuroma; Intradural; Spinal neoplasm

Ganglioneuromas most commonly arise from sympathetic ganglia [10]. These neoplasms may be located wherever ganglion cells are normally found from the skull base to the pelvis, including the adrenal medulla. We present a mature ganglion cell tumor within the dura of the thoracic spine that was causing progressive onset of lower extremity weakness and ataxia. To our knowledge there has been no ganglioneuroma reported to be completely intradural and extramedullary.

\section{Case Report}

A 56-year-old right-handed man was in good health until May 1987, when he noted the progressive onset of lower extremity weakness and ataxia. He was seen by an outside physician who felt his symptoms were consistent with a cerebrovascular accident. His condition deteriorated and he was subsequently unable to walk. He presented to the Ann Arbor Veterans Medical Center for further evaluation.

A neurological examination revealed $2 / 5$ strength in all muscle groups in the patient's lower extremities. Pinprick sensation was markedly decreased below the nipple line. Deep tendon reflexes were hyperreflexic

\footnotetext{
Address reprint requests to: Michael N. Bucci, M.D., Anderson Neurosurgical Associates, 109 Montgomery Drive, Anderson, South Carolina 29621.

Received February 27, 1989; accepted October 3, 1991
}

throughout the lower extremities along with markedly increased tone, left greater than right. Sustained clonus was noted at both ankles.

The patient subsequently underwent myelography, which revealed a complete block secondary to an intradural mass at T4. Computed tomography following myelography suggested an intradural extramedullary lesion. Preoperative magnetic resonance scanning confirmed the presence of an extramedullary lesion at the T4 level (Figure 1).

The patient was taken to surgery in July 1987 and underwent thoracic decompressive laminectomy from T3 through T5. Intraoperative ultrasonography confirmed the presence of an intradural lesion at the T3 level on the dorsal surface of the spinal cord. The dura was opened to reveal a well-circumscribed, extramedullary, oval-shaped mass measuring approximately $4 \mathrm{~cm} \times$ $3 \mathrm{~cm}$. Filamentous attachments secured the mass to the dorsal spinal cord, but they were removed easily and the mass was totally excised. Postoperatively the patient

Figure 1. Sagittal magnetic scan resonance demonstrating the intradural, extramedullary mass with compression of the adjacent spinal cord.

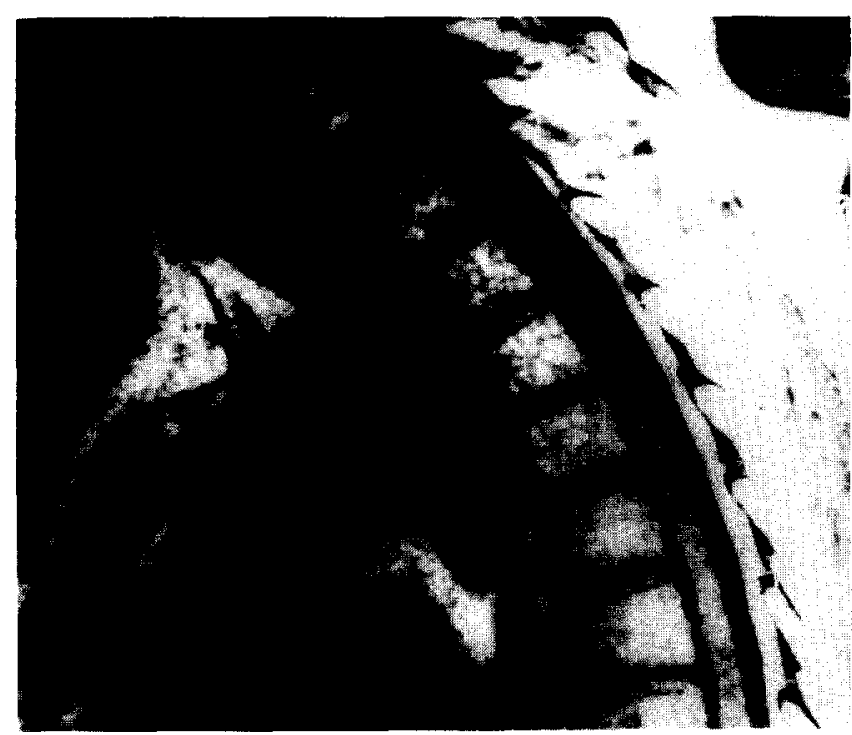




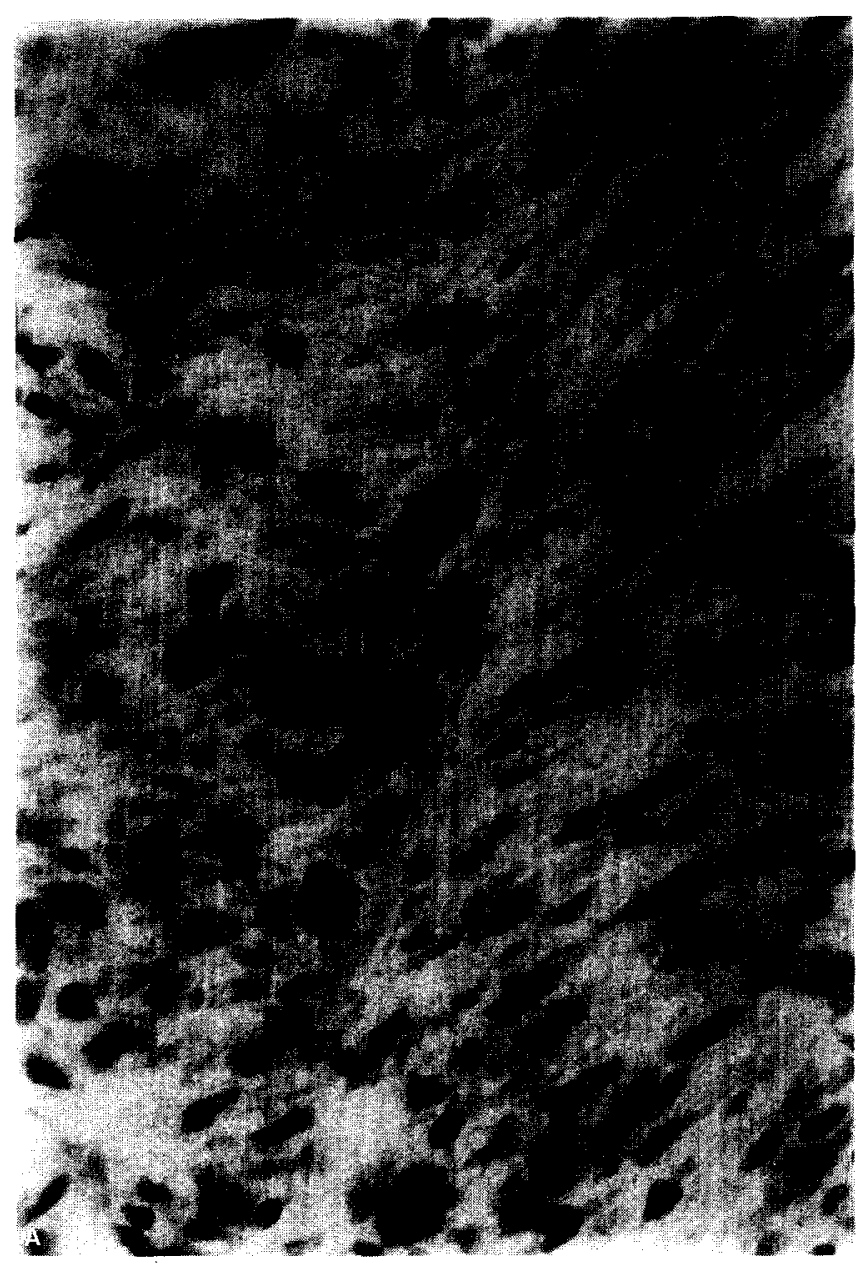

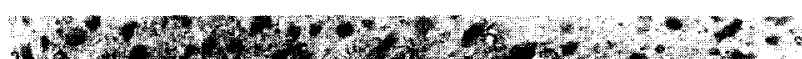
17.

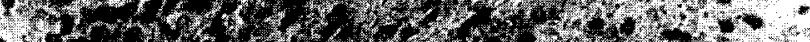

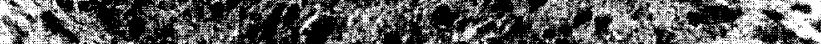

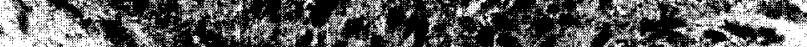

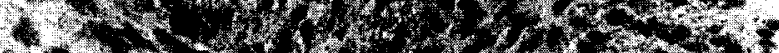

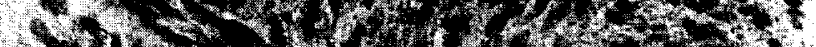

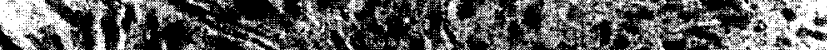

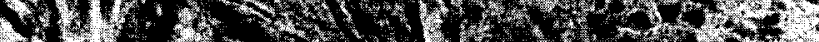

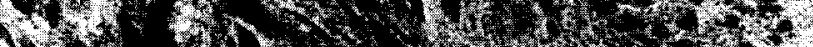

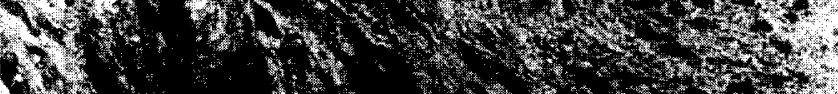

1)

(7)

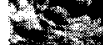

25

sit.

(t)

10.

(1).

W.

9.

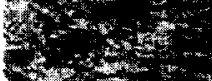

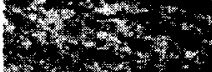

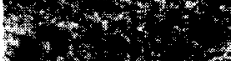

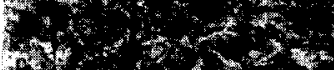

H.

a.

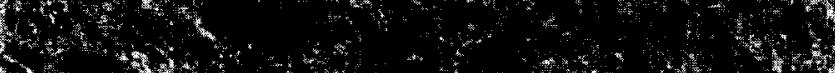

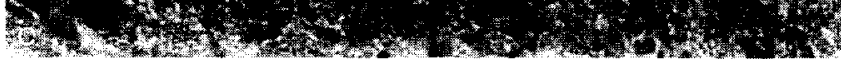

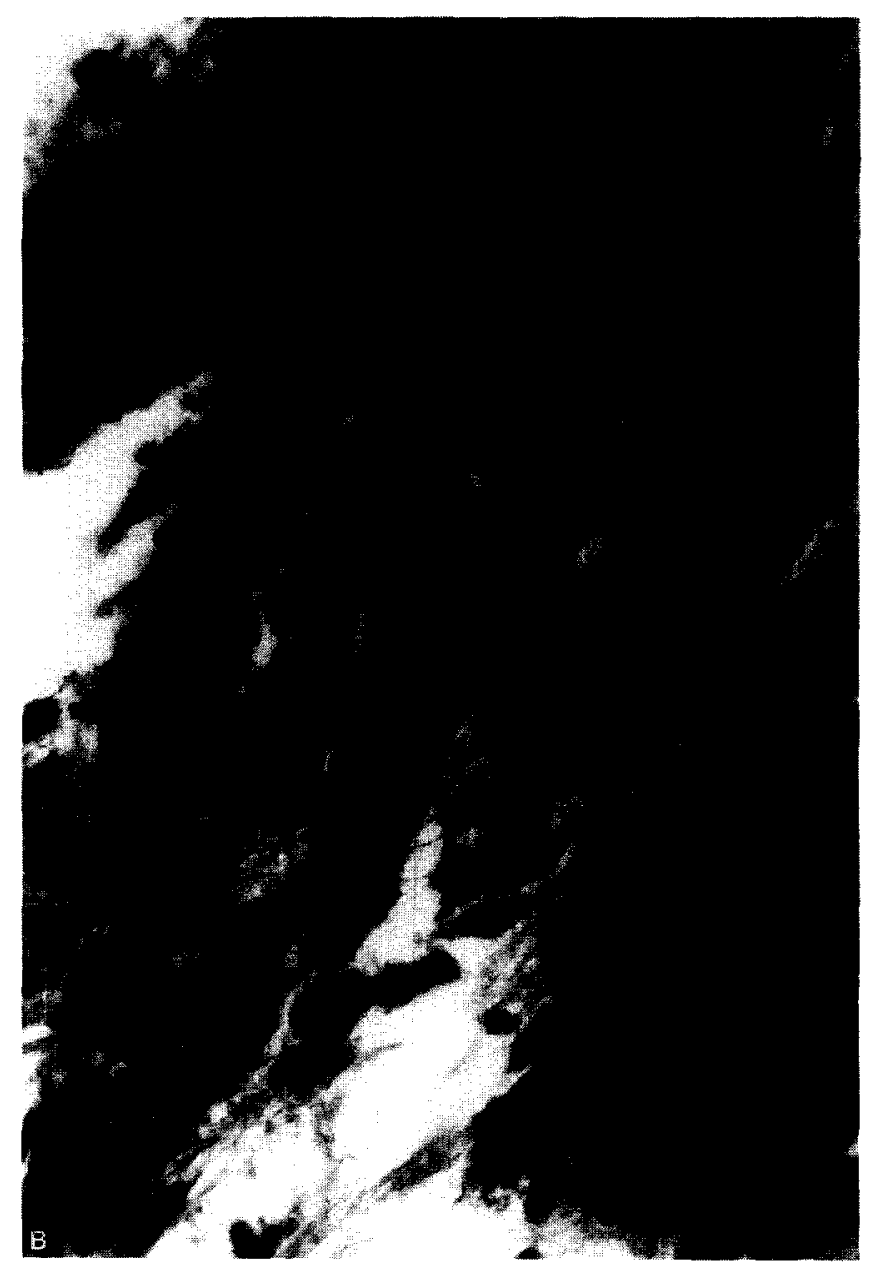

Figure 2. (A) High-power $(\times 400)$ view of the neoplasm illustrating the basic pattern of bundles of spindle cells. Occasional scattered larger cells that represent ganglion cells are apparent. (B) This higher-power view $(\times 400)$ includes a more typical cell in a background of small spindle cells. Satellite cells are not apparent. (C) This low-power $(\times 200)$ section was stained for S-100 protein and sbows diffuse staining of the spindle cell areas. Some of the ganglion cells also stain. 
improved dramatically and at the time of transfer to a rehabilitation center, he had $4 / 5$ strength distally throughout both lower extremities, with a marked decrease in his lower extremity tone and spasticity. The final pathological diagnosis was ganglioneuroma (Figure 2).

\section{Pathological Description}

The neoplasm consisted of interlacing bundles of spindle cells with scattered larger cells having abundant cytoplasm and nuclei with prominent nucleoli. The large cells generally had one nucleus and rarely two, as well as abundant cytoplasm, and they had the features of ganglion cells. In a few of these cells Nissl-type granules were noted with cresyl violet stain. Both the spindle cell component and some of the ganglion cells stained positively for S-100 protein, which is consistent with the neurogenic nature of the neoplasm.

\section{Discussion}

Ganglioneuroma is a benign neoplasm with well-differentiated ganglion cells in a spindle cell stroma resembling neurofibroma. They are slow-growing wellencapsulated tumors, round or oval, with occasional lobulations.

Complete removal of a ganglioneuroma usually effects a cure. They should be differentiated from the tumors with greater malignant potential that are known as gangliomas [6]. It is worth noting that a connective tissue stroma is a prominent feature of peripheral ganglioneuromas, yet it is rarely prominent in central ganglioneuromas, in which the stroma is mostly glial [5].

Ganglioneuromas are commonly seen in organs and tissue of neural crest origin, such as the adrenal medulla, the peripheral nervous system, and the organ of Zuckerkandl. Ganglion cell tumors arise as a defect in developmental embryogenesis, with multipotent embryonal neurocytes being deposited in abnormal positions [10]. Depending on the level of differentiation, mature forms such as ganglioneuromas or immature forms such as neuroblastomas arise [2]. They most commonly arise in the sympathetic chain ganglia, with the highest frequency in the thoracic region.

Central nervous system ganglioneuromas are rare and most often occur in children and young adults, with the most prevalent locations being the third ventricle and hypothalamus. Temporal and frontal lobe lesions are less common [6].

The spinal cord is more rarely affected with ganglioneuromas $[1,4,7]$. When they occur, they are frequently dumbell-shaped $[3,8]$. An association with Von Recklinghausen disease has been described [9].

Prognosis is favorable if total resection is achieved, particularly if the lesion is well encapsulated, as was the case with this patient [6].

\section{References}

1. Kalyanaraman UP, Henderson JP. Intramedullary ganglioneuroma of spinal cord: a clinicopathologic study. Hum Pathol $1982 ; 13: 952-5$.

2. Kernohan JW, Learmonth JR, Doyle JB. Neuroblastomas and gangliocytomas of the central nervous system. Brain 1932;55:287-311.

3. Oro JJ, Geise AW. Dumbbell ganglioneuroma of the lumbar spine associated with a herniated intervertebral disc: case report. Neurosurgery $1983 ; 13: 711-4$.

4. Rasmussen TB, Kernohan JW, Adson AW. Pathologic classification, with surgical consideration, of intraspinal tumors. Ann Surg. $1940 ; 11: 513-29$.

5. Robertson DM, Hendry WS, Vogel FS. Central ganglioneuroma: a case study using electron microscopy. J Neuropathol Exp Neurol 1964;23:692-705

6. Rubinstein LJ. Tumors of the central nervous system. 2nd ed. Washington, DC: Armed Forces Institute of Pathology, 1972:154-67

7. Scoville WB, Polcyn JL, Dunsmore RH. Spinal ganglioneuromas: end results and differential diagnosis. J Neuropathol Exp Neurol 1956;15:85-92.

8. Shepherd RH, Sutton D. Dumb-bell ganglioneuromata of the spine with a report of four cases. B J Surg 1958;45:305-17.

9. Sinclair JE, Yang YH. Ganglioneuromata of the spine associated with Von Recklinghausen's disease. J Neurosurg 1961;18:115-9.

10. Stout AP. Ganglioneuromas of the sympathetic nervous system. Surg Gynecol Obstet 1947;84:101-10. 